\title{
Effect of Activated Charcoal on Apixaban Pharmacokinetics in Healthy Subjects
}

\author{
Xiaoli Wang $\cdot$ Sabiha Mondal $\cdot$ Jessie Wang $\cdot$ \\ Giridhar Tirucherai · Donglu Zhang • \\ Rebecca A. Boyd · Charles Frost
}

Published online: 26 November 2013

(C) The Author(s) 2013. This article is published with open access at Springerlink.com

\begin{abstract}
Background Activated charcoal is commonly used to manage overdose or accidental ingestion of medicines. This study evaluated the effect of activated charcoal on apixaban exposure in human subjects.

Methods This was an open-label, three-treatment, threeperiod, randomized, crossover study of single-dose apixaban $(20 \mathrm{mg})$ administered alone and with activated charcoal given at 2 or $6 \mathrm{~h}$ post-dose to healthy subjects. Blood samples for assay of plasma apixaban concentration were collected up to $72 \mathrm{~h}$ post-dose. Pharmacokinetic parameters, including peak plasma concentration $\left(C_{\max }\right)$, time to $C_{\max }\left(T_{\max }\right)$, area under the concentration-time curve from time 0 to infinity $\left(\mathrm{AUC}_{\mathrm{INF}}\right)$, and terminal half-life $\left(T_{1 / 2}\right)$, were derived from apixaban plasma concentration-time data. A general linear mixed-effect model analysis of $C_{\max }$ and $\mathrm{AUC}_{\mathrm{INF}}$ was performed to estimate the effect of activated charcoal on apixaban exposure.
\end{abstract}

\section{Wang}

Discovery Medicine and Clinical Pharmacology, Bristol-Myers Squibb, Mail Stop E13-08, Route 206 and Province Line Road, Princeton, NJ 08543-4000, USA

\section{S. Mondal}

Pharmaceutical Product Development, Inc., 7551 Metro Center Drive, Suite 200, Austin, TX 78744, USA

\section{J. Wang}

Global Biometric Sciences, Bristol-Myers Squibb, Mail Stop E13-08, Route 206 and Province Line Road, Princeton, NJ 08543-4000, USA

J. Wang

PO Box 4000, Room J2123, Princeton, NJ 08543-4000, USA
Results A total of 18 subjects were treated and completed the study. $\mathrm{AUC}_{\mathrm{INF}}$ for apixaban without activated charcoal decreased by 50 and $28 \%$, respectively, when charcoal was administered at 2 and $6 \mathrm{~h}$ post-dose. Apixaban $C_{\max }$ and $T_{\max }$ were similar across treatments. The mean $T_{1 / 2}$ for apixaban alone $(13.4 \mathrm{~h})$ decreased to $\sim 5 \mathrm{~h}$ when activated charcoal was administered at 2 or $6 \mathrm{~h}$ post-dose. Overall, apixaban was well tolerated in this healthy population, and most adverse events were consistent with the known profile of activated charcoal.

Conclusion Administration of activated charcoal up to $6 \mathrm{~h}$ after apixaban reduced apixaban exposure and facilitated the elimination of apixaban. These results suggest that activated charcoal may be useful in the management of apixaban overdose or accidental ingestion.

\section{Introduction}

Apixaban is a highly selective, potent inhibitor of both free and prothrombinase-bound factor $\mathrm{Xa}[1,2]$. Apixaban has

G. Tirucherai · C. Frost $(\square)$

Discovery Medicine and Clinical Pharmacology, Bristol-Myers Squibb Company, Mail Stop E12-16, Route 206 and Province

Line Road, Princeton, NJ 08543-4000, USA

e-mail: charles.frost@bms.com

D. Zhang

82 Ketcham Road, Belle Mead, NJ 08502, USA

R. A. Boyd

Clinical Pharmacology, Primary Care, Pfizer Inc., 445 Eastern Point Road, Groton, CT 06340, USA 
been approved in multiple countries for the prevention of stroke and systemic embolism in patients with non-valvular atrial fibrillation [3, 4] and for thromboprophylaxis following elective knee or hip replacement surgery [5, 6]. It is also under development for the treatment of acute symptomatic deep vein thrombosis [7]. Although the risk of bleeding complications with apixaban is lower than that with warfarin in patients with atrial fibrillation [4], the potential for bleeding remains a concern with all anticoagulants in the event of overdose or accidental ingestion. Agents such as protamine, fresh frozen plasma, prothrombin complex concentrate, and vitamin $\mathrm{K}$ have been used successfully to reverse the anticoagulant effects of heparin derivatives and warfarin [8-12]. Currently there is no consensus on how to reverse the anticoagulant effects of novel oral anticoagulants such as apixaban, dabigatran, and rivaroxaban. Thus, options to manage the accidental ingestion or overdose of these agents are desirable. Given that novel oral anticoagulants are direct reversible inhibitors, their anticoagulant effect could be reduced by limiting systemic exposure through decreased absorption, enhanced elimination, or both.

Activated charcoal adsorbs drugs present in the gastrointestinal (GI) tract, reducing the amount of drug available for absorption into the systemic circulation [13-15]. It may also enhance elimination by interrupting reabsorption of drugs that are excreted directly into the intestinal tract from the systemic circulation (enteroenteric recycling) or in bile (enterohepatic recycling) [16-21]. In human volunteer studies, administration of activated charcoal for up to $4 \mathrm{~h}$ after overdose limited exposure to many different chemicals to varying degrees, and was effective in treating overdose with a wide variety of drugs [22, 23], including digoxin, phenytoin, carbamazepine, and acetaminophen [24, 25]. However, no consistent relationship between the chemical characteristics of a drug and the maximum adsorptive capacity of activated charcoal has been identified [26].

Apixaban is formulated as an immediate-release tablet. Apixaban is rapidly absorbed following oral administration, reaching peak plasma concentration $\left(C_{\max }\right)$ typically within $3 \mathrm{~h}$ of administration. Oral bioavailability is approximately $50 \%$, and pharmacokinetics $(\mathrm{PK})$ are linear over the therapeutic dose range. Absorption of oral apixaban appears to be mainly within the small intestine [27]. Food and changes in gastric $\mathrm{pH}$ have no clinically relevant effect on apixaban exposure [28, 29]. Elimination occurs through multiple pathways, including metabolism and renal and biliary excretion, with a terminal half-life $\left(T_{1 / 2}\right)$ of approximately $12 \mathrm{~h}[30,31]$. Intravenous studies in bileduct cannulated (BDC) beagle dogs and rats have indicated that direct intestinal excretion may also be involved in the elimination of apixaban [31-33], and further studies in dogs have demonstrated that activated charcoal reduces apixaban bioavailability and may also facilitate elimination by interrupting enteroenteric recycling [33]. The present study was designed to assess the effect of activated charcoal on apixaban PK in healthy human subjects.

\section{Methods}

\subsection{Study Design and Treatments}

This was a single-center, open-label, randomized, threetreatment, three-period crossover study conducted in healthy human subjects. Treatments administered were as follows: (A) apixaban $20 \mathrm{mg}$ (four 5-mg tablets as a single dose); (B) apixaban $20 \mathrm{mg}$, with activated charcoal $50 \mathrm{~g}$ administered at $2 \mathrm{~h}$ post-dose; and (C) apixaban $20 \mathrm{mg}$, with activated charcoal $50 \mathrm{~g}$ administered at $6 \mathrm{~h}$ post-dose. For all treatments, apixaban was administered after a minimum 10 -h fast.

The 20-mg dose of apixaban used in this study represents the high end of the dose range evaluated in clinical trials and is several-fold higher than the currently approved dosages for thromboprophylaxis following knee and hip replacement surgery (2.5 mg twice daily) and for the prevention of stroke and systemic embolism in patients with atrial fibrillation (5 mg twice daily). The 50-g dose of activated charcoal selected for this study is the standard for treating overdose in adults [34]. Charcoal was administered as Actidose ${ }^{\circledR}$ (Paddock Laboratories, Inc., Minneapolis, MN, USA), an aqueous suspension of $50 \mathrm{~g}$ of activated charcoal and $96 \mathrm{~g}$ of sorbitol in $240 \mathrm{~mL}$ of water. Administration of activated charcoal at $2 \mathrm{~h}$ after apixaban dosing was selected to demonstrate the effect of charcoal soon after apixaban ingestion; $2 \mathrm{~h}$ is similar to the time frame that often elapses before treating an overdose in the emergency room. The 6-h postdose time point was also chosen for administration of activated charcoal to assess whether activated charcoal is effective at a time when the majority of apixaban absorption has already occurred.

Subjects were randomly assigned to one of six treatment sequences with a washout period of at least 4 days between treatments. Randomization was carried out according to a computer-generated scheme. Subjects were required to remain at the clinical facility for the duration of the study.

The study protocol was approved by IntegReview Ethical Review Board (Austin, TX, USA) and conducted in compliance with all local regulations, the Declaration of Helsinki, and the International Conference on Harmonisation Guidelines for Good Clinical Practice.

\subsection{Study Population}

The study recruited healthy male and female subjects (defined as normal with respect to medical history, physical examination, 12-lead electrocardiogram [ECG], and 
clinical laboratory determinations) who were 18-45 years of age and had a body mass index of $18-32 \mathrm{~kg} / \mathrm{m}^{2}$. Subjects provided written informed consent prior to study commencement.

Key exclusion criteria included any significant chronic or acute medical illness, any history or evidence of abnormal bleeding or coagulation disorder, intracranial hemorrhage, any abnormal bleeding or coagulation disorder in a first-degree relative, any history of GI-related disorders that would impact absorption of apixaban or otherwise influence apixaban PK, and any contraindication to the use of activated charcoal. Subjects were also excluded if they smoked more than ten cigarettes per day, were unable or unwilling to comply with the dietary requirements of the study, or were unable or unwilling to use adequate contraception throughout the study. In addition, female subjects were excluded if they were pregnant or breastfeeding.

\subsection{Pharmacokinetic Sampling and Analysis}

Blood samples for PK analysis were collected using venipuncture or an indwelling catheter immediately before dosing with apixaban and at $0.5,1,1.5,2,2.5,3,4,6,6.5$, $8,10,12,18,24,36,48$, and 72 h post-dose. Blood samples at 2 or $6 \mathrm{~h}$ post-dose were taken immediately prior to administration of activated charcoal, where applicable. Apixaban plasma concentration was determined using a validated liquid chromatography/atmospheric pressure ionization tandem mass spectrometry method by Intertek Pharmaceutical Services (formally known as Alta Analytical Laboratory, El Dorado Hills, CA, USA), with a lower limit of quantification of $1 \mathrm{ng} / \mathrm{mL}$. The between-run and within-run variability, expressed as coefficient of variation, for apixaban in quality-control samples was $\leq 5.58$ and $\leq 7.54 \%$, respectively, with deviations from the nominal concentration of no more than $\pm 7.14 \%$. Stability of apixaban in human plasma was established for at least 864 days at $-20{ }^{\circ} \mathrm{C}$, and all samples were analyzed within this period of analyte stability. For calculation of PK parameters, plasma concentrations with values below the lower limit of quantification before the first measurable concentration were treated as zero, and treated as missing at all other times.

Subjects were excluded from the PK analysis if they experienced emesis within $6 \mathrm{~h}$ of apixaban dosing (all regimens) or within $30 \mathrm{~min}$ of activated charcoal administration (regimens $\mathrm{B}$ and $\mathrm{C}$ ). Apixaban $\mathrm{PK}$ parameters were derived from plasma concentration versus time data with non-compartmental methods using Phoenix ${ }^{\circledR}$ WinNonlin ${ }^{\circledR}$, version 6.1 (Pharsight, St. Louis, MO, USA). The $C_{\max }$ and time to reach $C_{\max }\left(T_{\max }\right)$ were obtained from experimental observations. The terminal-phase rate constant $(\lambda)$ was calculated using linear regression of the log-linear plasma concentration-time curve. The $T_{1 / 2}$ was estimated as $\ln 2 / \lambda$. The area under the concentration-time curve from time 0 to the last measurable plasma concentration $\left(\mathrm{AUC}_{(0-T)}\right)$ was calculated using the linear-up, logdown trapezoidal rule. The AUC from time 0 to infinity $\left(\mathrm{AUC}_{\mathrm{INF}}\right)$ was calculated by summing $\mathrm{AUC}_{(0-T)}$ and the extrapolated area, determined by dividing the last predicted concentration by $\lambda[35]$.

\subsection{Safety Assessments}

Safety assessments included adverse events, clinical laboratory tests, vital sign measurements, physical examinations, and 12-lead ECGs. Adverse events were collected from spontaneous reports-elicited through open-ended questioning, examination, or evaluation of the subjectand reviewed for clinical significance and relation to study drug use. All adverse events were coded by system organ class, severity, and preferred term, according to the Medical Dictionary for Regulatory Activities (MedDRA, version 14.0). Blood and urine samples for clinical laboratory tests, including hematology, serum chemistry, and urinalysis, were collected at screening on the day before study commencement and on the second day of each treatment period, as well as at discharge or early termination from the study. Vital signs were assessed at screening, at study commencement, before administration of each apixaban dose, and at study termination. Twelve-lead ECGs were recorded at screening, study commencement, and study discharge. Any marked abnormalities in clinical test results or vital signs were assessed for clinical significance by the investigator.

\subsection{Statistical Methods}

The sample size was not determined based on statistical power considerations. Assuming log-normal distributions of $\mathrm{AUC}_{\mathrm{INF}}$ and $C_{\max }$, and intra-subject standard deviations of 0.20 for apixaban $\log \left(C_{\max }\right)$ and 0.19 for apixaban $\log$ (AUC) (data on file, protocol CV185033, Bristol-Myers Squibb Company), data from 12 subjects were expected to provide $90 \%$ confidence that the geometric mean ratio of apixaban, with and without activated charcoal, was within 14 and $13 \%$ of the true values for $C_{\max }$ and $\mathrm{AUC}$, respectively.

A general linear mixed-effect model analysis was performed on $\ln \left(C_{\text {max }}\right), \ln \left(\mathrm{AUC}_{(0-T)}\right)$, and $\ln \left(\mathrm{AUC}_{\mathrm{INF}}\right)$ using treatment, period, and sequence as fixed effects and measurements within subjects as repeated measures. Point estimates and $90 \%$ confidence intervals (CIs) for the differences on the $\log$ scale were exponentiated to obtain estimates for the ratios of geometric means and for $90 \%$ 
CIs on the original scale. Apixaban alone was the reference treatment. PK parameters were summarized using descriptive statistics; geometric means and coefficients of variation were presented for $C_{\max }, \mathrm{AUC}_{(0-T)}$, and $\mathrm{AUC}_{\mathrm{INF}}$; medians, minima, and maxima were reported for $T_{\max }$; and means and standard deviations were reported for $T_{1 / 2}$. All statistical analyses were carried out using SAS, version 9.1 or higher (SAS Institute, Cary, NC, USA).

\section{Results}

\subsection{Subject Disposition}

The clinical phase of the study took place from 6-17 May 2011; 18 subjects were enrolled, all of whom completed the study. Demographics and baseline characteristics of the study population are shown in Table 1 . All subjects were included in the summary of safety data. Five subjects were excluded from the PK analysis because of emesis that occurred after administration of the activated charcoal suspension (four receiving activated charcoal at $2 \mathrm{~h}$ after apixaban, and one receiving activated charcoal at $6 \mathrm{~h}$ after apixaban).

\subsection{Pharmacokinetics}

The mean plasma concentration-time profiles for apixaban are shown in Fig. 1; PK parameters are summarized in Table 2. Following a single oral 20 -mg dose, mean plasma

Table 1 Demographic and baseline characteristics

\begin{tabular}{ll}
\hline Characteristic & Overall $(n=18)$ \\
\hline Age (years) & $31.8(8.3)$ \\
Mean (SD) & $18-45$ \\
Range & \\
Sex, $n(\%)$ & $10(55.6)$ \\
Male & $8(44.4)$ \\
Female & \\
Race, $n(\%)$ & $14(77.8)$ \\
White & $4(22.2)$ \\
Black or African American & \\
Height (cm) & $169.4(14.6)$ \\
Mean (SD) & $147.3-198.5$ \\
Range & \\
Weight (kg) & $72.2(18.6)$ \\
Mean (SD) & $51.4-111.1$ \\
Range & \\
BMI (kg/m $\left.{ }^{2}\right)$ & $24.7(2.7)$ \\
Mean (SD) & $20.8-29.2$ \\
Range &
\end{tabular}

$B M I$ body mass index, $S D$ standard deviation concentrations of apixaban were quantifiable for up to $72 \mathrm{~h}$ without activated charcoal, but only for up to $48 \mathrm{~h}$ with activated charcoal administered at 2 and $6 \mathrm{~h}$ post-dose (Fig. 1). Activated charcoal had no effect on the $C_{\max }$ or $T_{\max }$ of apixaban, whereas the AUC and $T_{1 / 2}$ were reduced. Apixaban exposure decreased by 50 and $28 \%$, respectively, when activated charcoal was administered post-dose at $2 \mathrm{~h}$ (ratio of adjusted geometric mean for $\mathrm{AUC}_{\mathrm{INF}}$ 0.496; $90 \%$ CI $0.450-0.547$ ) and $6 \mathrm{~h}$ (ratio of adjusted geometric mean for $\mathrm{AUC}_{\mathrm{INF}} 0.723 ; 90 \%$ CI 0.661-0.792). The mean $T_{1 / 2}$ for apixaban $(13.4 \mathrm{~h})$ decreased to 5.3 and $4.9 \mathrm{~h}$, respectively, with 2- and 6-h post-dose administration of activated charcoal.

\subsection{Safety}

A total of 15 subjects reported 102 adverse events during the study, all of which resolved by study completion. Most reported adverse events were considered mild $(38.9 \%)$ or moderate $(44.4 \%)$ in severity. There were no withdrawals from the study because of adverse events.

Overall, a higher proportion of subjects reported adverse events following 2- and 6-h post-dose administration of activated charcoal (72.2 and $77.8 \%$, respectively) compared with apixaban alone (16.7 \%). Adverse events reported by at least two subjects $(11.1 \%)$ included diarrhea, nausea, abdominal pain or discomfort, vomiting, abdominal distension, eructation, flatulence, asthenia, and oropharyngeal pain. All other adverse events were reported by one subject each, including an instance of mild gingival bleeding that occurred following a 2-h post-dose administration of activated charcoal and resolved without treatment. GI disorders, which occurred primarily with the activated charcoal-containing regimens, were consistent with the known tolerability profile of activated charcoal [34]; seven of the eight emeses occurred within $2 \mathrm{~h}$ following administration of activated charcoal.

There were no clinically significant laboratory abnormalities and no apparent treatment-related trends observed in clinical laboratory results, vital sign measurements, physical examination findings, or 12-lead ECG results.

\section{Discussion}

The $C_{\max }$ of apixaban typically occurs approximately $3 \mathrm{~h}$ following administration. Therefore, activated charcoal was expected to decrease the bioavailability of apixaban when administered $2 \mathrm{~h}$ after the apixaban dose. Administration of activated charcoal at $6 \mathrm{~h}$ post-dose was not expected to have a significant impact, since apixaban was expected to be largely through its initial absorptive phase by that time.

The results of this study confirm that activated charcoal administered $2 \mathrm{~h}$ after apixaban decreases apixaban exposure, as evidenced by a $50 \%$ decrease in the apixaban 
Fig. 1 Mean (standard deviation) plasma concentration-time profiles for apixaban alone and with activated charcoal given at 2 and $6 \mathrm{~h}$ post-dose, using linear (upper panel) and semilogarithmic (lower panel) scales
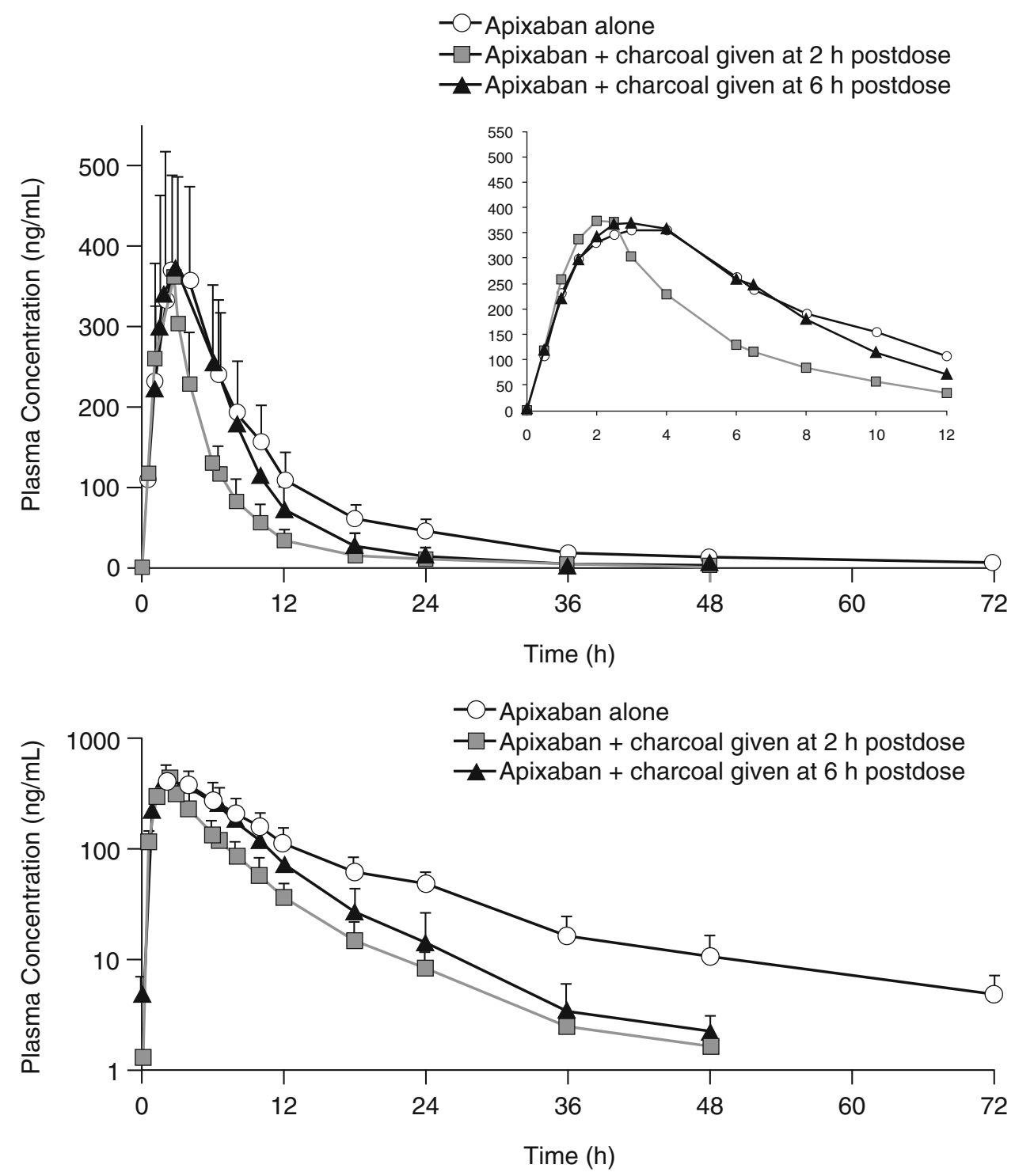

$\mathrm{AUC}_{\mathrm{INF}}$. Based on these findings, activated charcoal may be useful in the management of apixaban overdose or accidental ingestion. The $28 \%$ decrease in apixaban exposure observed following administration of activated charcoal at $6 \mathrm{~h}$ post-dose suggests that the effect of activated charcoal may be due to more than a decrease in apixaban bioavailability. Furthermore, the decrease in the $T_{1 / 2}$ of apixaban from $\sim 13$ to $\sim 5 \mathrm{~h}$ when activated charcoal was given at 2 or $6 \mathrm{~h}$ post-dose indicates that activated charcoal increases the elimination of apixaban in the GI tract. These data suggest that apixaban may undergo some degree of recycling between the systemic circulation and the GI tract, and that the presence of activated charcoal in the GI tract interrupted this recycling, resulting in enhanced elimination of apixaban via the feces. The apparent increased elimination of apixaban in the presence of charcoal could be potentially useful in situations other than overdose involving higher than desirable exposure of apixaban.

Enterohepatic recycling of apixaban does not appear to be a likely pathway since biliary excretion of apixaban in humans is limited. Biliary aspirate has been collected from healthy subjects administered a single oral 20-mg dose of radiolabeled apixaban [30]. In that study, bile collection began $3 \mathrm{~h}$ after apixaban administration, continued for $5 \mathrm{~h}$, and concluded with the administration of cholecystokinin to ensure complete emptying of the gallbladder. Biliary excretion of unchanged apixaban accounted for less than $3 \%$ of the total recovered radioactivity, with less than half of that attributed to unchanged apixaban. Thus, adsorption of this limited amount of apixaban to activated charcoal would not result in the $28 \%$ decrease in apixaban AUC or the shorter $T_{1 / 2}$ observed following administration of charcoal $6 \mathrm{~h}$ after apixaban. 
Table 2 Apixaban plasma pharmacokinetic parameters by treatment

\begin{tabular}{|c|c|c|c|c|}
\hline & \multicolumn{3}{|l|}{ Treatment } & \multirow[b]{2}{*}{$\begin{array}{l}\text { Ratio of adjusted } \\
\text { geometric mean } \\
(90 \% \mathrm{CI})^{\mathrm{b}}\end{array}$} \\
\hline & $\begin{array}{l}\text { A } \\
\text { Apixaban } \\
20 \text { mg alone } \\
(n=18)\end{array}$ & $\begin{array}{l}\text { B } \\
\text { Apixaban } 20 \mathrm{mg}+ \\
\text { activated charcoal } \\
2 \mathrm{~h} \text { after apixaban } \\
(n=14)^{\mathrm{a}}\end{array}$ & $\begin{array}{l}\mathrm{C} \\
\text { Apixaban } 20 \mathrm{mg}+ \\
\text { activated charcoal } \\
6 \mathrm{~h} \text { after apixaban } \\
(n=17)^{\mathrm{a}}\end{array}$ & \\
\hline $\operatorname{AUC}_{(0-T)}(\mathrm{ng} \cdot \mathrm{h} / \mathrm{mL})$ & $4,080(27)$ & $2,007(30)$ & $2,954(32)$ & $\begin{array}{l}\text { B vs A: } 0.503(0.456-0.554) \\
\text { C vs A: } 0.737(0.674-0.806)\end{array}$ \\
\hline $\mathrm{AUC}_{\mathrm{INF}}(\mathrm{ng} \cdot \mathrm{h} / \mathrm{mL})$ & $4,185(26)$ & $2,034(30)$ & $2,976(32)$ & $\begin{array}{l}\text { B vs A: } 0.496(0.450-0.547) \\
\text { C vs A: } 0.723(0.661-0.792)\end{array}$ \\
\hline$C_{\max }(\mathrm{ng} / \mathrm{mL})$ & $380(30)$ & $366(34)$ & $383(30)$ & $\begin{array}{l}\text { B vs A: } 0.999(0.903-1.105) \\
\text { C vs A: } 1.030(0.939-1.130)\end{array}$ \\
\hline$T_{\max }(\mathrm{h})$ & $2.5(1.0-4.0)$ & $2.5(1.5-2.5)$ & $2.5(1.5-4.0)$ & \\
\hline$T_{1 / 2}(\mathrm{~h})$ & $13.4(5.1)$ & $5.3(1.1)$ & $4.9(1.2)$ & \\
\hline
\end{tabular}

Geometric mean (\% coefficient of variation) for $\mathrm{AUC}_{(0-T)}, \mathrm{AUC}_{\mathrm{INF}}$, and $C_{\max }$. Median (range) for $T_{\max }$. Mean (SD) for $T_{1 / 2}$

$A U C_{(0-T)}$ area under the plasma concentration-time curve from time zero to last observed concentration, $A U C_{I N F}$ area under the plasma concentration-time curve from time zero to infinity, $C_{\max }$ peak plasma concentration, $C I$ confidence interval, $S D$ standard deviation, $T_{1 / 2}$ apparent terminal half-life, $T_{\max }$ time to $C_{\max }$

${ }^{a}$ Four subjects were excluded from the analysis of treatment B and one from the analysis of treatment $\mathrm{C}$ because of emesis

${ }^{\mathrm{b}}$ Results were estimated using the general linear mixed-effect model

Alternatively, apixaban may undergo enteroenteric recycling (i.e., reabsorption of drug excreted from the systemic circulation directly into the intestine). Animal studies provide support for the involvement of enteroenteric recycling in the disposition of apixaban [31, 33]. Apixaban was recovered from the feces of BDC rats and dogs administered intravenous $\left[{ }^{14} \mathrm{C}\right]$ apixaban. Approximately $20-30 \%$ and $40-50 \%$ of the dose, respectively, was found in the feces of BDC rats and dogs. Administration of activated charcoal to BDC dogs increased fecal recovery and apparent systemic clearance, suggesting that activated charcoal prevents reabsorption of apixaban by interrupting enteroenteric recycling [33]. A similar study in BDC rats administered intravenous apixaban showed a $36 \%$ increase in fecal recovery following oral administration of activated charcoal [33]. While apixaban is not a substrate of the major uptake transporters, apixaban is a P-glycoprotein (P-gp) and breast cancer resistance protein (BCRP) substrate [36]. Further investigation in rats suggested that the intestinal efflux transporters P-gp and BCRP may be involved in the intestinal excretion of apixaban. When intravenous apixaban was administered to BDC rats in the presence of GF-120918, an inhibitor of P-gp and BCRP, fecal recovery was reduced by $34 \%$ [33].

Activated charcoal reduces systemic exposure to a wide variety of orally administered drugs in humans by adsorbing the drug in the GI tract and preventing absorption. However, for some drugs that are excreted into the GI tract, either via bile or across the GI mucosa, elimination is also enhanced, resulting in a shorter half-life in the presence of charcoal [16-19, 37, 38]. Presumably this occurs because adsorption of the drug to charcoal creates an increased concentration gradient for excretion into the lumen of the GI tract and/or because reabsorption is prevented, either or both of which can increase the rate of elimination from the body $[18,19]$. Thus, the decreased half-life of apixaban in the presence of activated charcoal in this study is consistent with increased elimination into the GI tract and/or decreased reabsorption, resulting in an increased rate of elimination from the body. It should be noted that an activated charcoal product containing sorbitol, Actidose ${ }^{\circledR}$, was used in this study to improve the palatability of the activated charcoal preparation in this healthy volunteer population. Activated charcoal-containing sorbitol products are not recommended because of the increased risk of emesis and aspiration [39].

Absorption throughout the GI tract, resulting in a prolonged absorption phase, is another possible explanation for the findings of this study; however, apixaban appears to be most readily absorbed in the upper small intestine, based on the results of a study evaluating the potential for regional differences in the absorption of apixaban [27]. In that three-way crossover study, a single dose of apixaban $2.5 \mathrm{mg}$ as solution was administered orally or delivered to either the distal small bowel or the ascending colon via an Enterion $^{\mathrm{TM}}$ capsule. Compared with oral administration, the $C_{\max }$ and $\mathrm{AUC}_{(0-T)}$ for apixaban were approximately $60 \%$ lower when the drug was released in the distal small 
bowel; $C_{\max }$ and $\mathrm{AUC}_{(0-T)}$ were 90 and $84 \%$ lower, respectively, when apixaban was released in the ascending colon [27]. These results indicate that the relative bioavailability of apixaban is significantly decreased in the distal GI tract; therefore, adsorption of apixaban to activated charcoal in the distal GI tract would not be expected to have a significant effect on apixaban exposure [27].

The objective of this study was to assess the effect of activated charcoal on apixaban exposure. It was not designed to identify the specific mechanisms by which activated charcoal affects apixaban disposition. Therefore, evaluation of these data through compartmental analyses or other modelling approaches, such as that described by Friberg et al. [40] and Isbister et al. [41], may provide a more complete understanding of charcoal's effect on apixaban bioavailability versus clearance. The role of enteroenteric recirculation in apixaban disposition could be further characterized through additional clinical study; for example, an assessment of intestinal recovery following intravenous administration of radiolabeled apixaban. While the effect of activated charcoal on apixaban exposure is evident from the results of this study, its effectiveness in patients following an apixaban overdose or in other situations that warrant reduction of apixaban exposure remains to be determined. Additional factors encountered in the clinical setting, such as the size of the overdose or the length of time that has elapsed before the patient receives activated charcoal, may be influential when considering potential treatment strategies.

In summary, apixaban was well tolerated in the healthy subjects in this study, with the majority of reported adverse events being consistent with the known adverse event profile of activated charcoal [42]. Administration of activated charcoal up to $6 \mathrm{~h}$ after apixaban ingestion resulted in a decrease in apixaban exposure. Activated charcoal appears to both reduce the bioavailability and interrupt the enteroenteric recycling of apixaban, leading to a more rapid elimination of apixaban. The results of this study suggest that activated charcoal administration may be useful in the clinical management of apixaban overdose or other clinical situations that warrant a reduction in apixaban exposure.

Acknowledgments This study was conducted by Pharmaceutical Product Development, Inc. (PPD), funded by Bristol-Myers Squibb Company (BMS) and Pfizer Inc. The authors would like to thank BMS employees Janice Pursley, Amira Elsrougy, Ming Chang, and Shuvo Rafiq and former employee Nico Pannacciulli for their contributions to the completion of the study; Mark Thomas and the PPD staff for their contribution to the conduct and reporting of the study; and Frank LaCreta for his valuable review of the manuscript. Professional medical writing and editorial assistance was provided by Andy Shepherd at Caudex Medical, and funded by BMS and Pfizer.

Conflict of interest SM is an independent contractor for PPD. All other authors are employees of BMS or Pfizer Inc.
Open Access This article is distributed under the terms of the Creative Commons Attribution Noncommercial License which permits any noncommercial use, distribution, and reproduction in any medium, provided the original author(s) and the source are credited.

\section{References}

1. Pinto DJ, Orwat MJ, Koch S, et al. Discovery of 1-(4-methoxyphenyl)-7-oxo-6-(4-(2-oxopiperidin-1-yl)phenyl)-4,5,6,7-tetrahydro-1H-pyrazolo[3,4-c]pyridine-3-carboxamide (apixaban, BMS562247), a highly potent, selective, efficacious, and orally bioavailable inhibitor of blood coagulation factor Xa. J Med Chem. 2007;50(22):5339-56.

2. Wong PC, Crain EJ, Xin B, et al. Apixaban, an oral, direct and highly selective factor Xa inhibitor: in vitro, antithrombotic and antihemostatic studies. J Thromb Haemost. 2008;6(5):820-9.

3. Connolly SJ, Eikelboom J, Joyner C, et al. Apixaban in patients with atrial fibrillation. N Engl J Med. 2011;364(9):806-17.

4. Granger CB, Alexander JH, McMurray JJ, et al. Apixaban versus warfarin in patients with atrial fibrillation. $\mathrm{N}$ Engl $\mathrm{J}$ Med. 2011;365(11):981-92.

5. Lassen MR, Raskob GE, Gallus A, et al. Apixaban versus enoxaparin for thromboprophylaxis after knee replacement (ADVANCE-2): a randomised double-blind trial. Lancet. 2010;375(9717):807-15.

6. Lassen MR, Gallus A, Raskob GE, et al. Apixaban versus enoxaparin for thromboprophylaxis after hip replacement. N Engl J Med. 2010;363(26):2487-98.

7. Buller H, Deitchman D, Prins M, et al. Efficacy and safety of the oral direct factor $\mathrm{Xa}$ inhibitor apixaban for symptomatic deep vein thrombosis. The Botticelli DVT dose-ranging study. J Thromb Haemost. 2008;6(8):1313-8.

8. Wolzt M, Weltermann A, Nieszpaur-Los M, et al. Studies on the neutralizing effects of protamine on unfractionated and low molecular weight heparin (Fragmin) at the site of activation of the coagulation system in man. Thromb Haemost. 1995;73(3): 439-43.

9. Vavra KA, Lutz MF, Smythe MA. Recombinant factor VIIa to manage major bleeding from newer parenteral anticoagulants. Ann Pharmacother. 2010;44(4):718-26.

10. Massonnet-Castel S, Pelissier E, Bara L, et al. Partial reversal of low molecular weight heparin (PK 10169) anti-Xa activity by protamine sulfate: in vitro and in vivo study during cardiac surgery with extracorporeal circulation. Haemostasis. 1986;16(2):139-46.

11. Majeed A, Eelde A, Agren A, et al. Thromboembolic safety and efficacy of prothrombin complex concentrates in the emergency reversal of warfarin coagulopathy. Thromb Res. 2012;129(2): $146-51$.

12. Ilyas C, Beyer GM, Dutton RP, et al. Recombinant factor VIIa for warfarin-associated intracranial bleeding. J Clin Anesth. 2008;20(4):276-9.

13. Green R, Grierson R, Sitar DS, et al. How long after drug ingestion is activated charcoal still effective? J Toxicol Clin Toxicol. 2001;39(6):601-5.

14. Laine K, Kivisto KT, Laakso I, et al. Prevention of amlodipine absorption by activated charcoal: effect of delay in charcoal administration. Br J Clin Pharmacol. 1997;43(1):29-33.

15. Yeates PJ, Thomas SH. Effectiveness of delayed activated charcoal administration in simulated paracetamol (acetaminophen) overdose. Br J Clin Pharmacol. 2000;49(1):11-4.

16. Berg MJ, Berlinger WG, Goldberg MJ, et al. Acceleration of the body clearance of phenobarbital by oral activated charcoal. N Engl J Med. 1982;307(11):642-4. 
17. Lalonde RL, Deshpande R, Hamilton PP, et al. Acceleration of digoxin clearance by activated charcoal. Clin Pharmacol Ther. 1985;37(4):367-71.

18. Levy G. Gastrointestinal clearance of drugs with activated charcoal. N Engl J Med. 1982;307(11):676-8.

19. Neuvonen PJ. Clinical pharmacokinetics of oral activated charcoal in acute intoxications. Clin Pharmacokinet. 1982;7(6):465-89.

20. Reissell P, Manninen V. Effect of administration of activated charcoal and fibre on absorption, excretion and steady state blood levels of digoxin and digitoxin. Evidence for intestinal secretion of the glycosides. Acta Med Scand Suppl. 1982;668:88-90.

21. Stass H, Kubitza D, Moller JG, et al. Influence of activated charcoal on the pharmacokinetics of moxifloxacin following intravenous and oral administration of a $400 \mathrm{mg}$ single dose to healthy males. Br J Clin Pharmacol. 2005;59(5):536-41.

22. Cooney DO. Activated charcoal in medical applications. New York: Marcel Dekker; 1995.

23. Isbister GK, Kumar VV. Indications for single-dose activated charcoal administration in acute overdose. Curr Opin Crit Care. 2011;17(4):351-7.

24. Neuvonen PJ, Elfving SM, Elonen E. Reduction of absorption of digoxin, phenytoin and aspirin by activated charcoal in man. Eur J Clin Pharmacol. 1978;13(3):213-8.

25. Neuvonen PJ, Elonen E. Effect of activated charcoal on absorption and elimination of phenobarbitone, carbamazepine and phenylbutazone in man. Eur J Clin Pharmacol. 1980;17(1):51-7.

26. al-Shareef AH, Buss DC, Routledge PA. Drug adsorption to charcoals and anionic binding resins. Hum Exp Toxicol. 1990;9(2):95-7.

27. Frost C, Wang X, Nepal S, et al. Assessment of the sites of gastrointestinal absorption of apixaban in healthy subjects. Presented at: 2013 Annual Meeting of the American College of Clinical Pharmacology. September 22-24, 2013. Bethesda, MD, USA.

28. Frost C, Wang J, Nepal S, et al. Apixaban, an oral, direct factor Xa inhibitor: single-dose safety, pharmacokinetics, pharmacodynamics and food effect in healthy subjects. Br J Clin Pharmacol. 2013;75(2):476-87.

29. Upreti VV, Song Y, Wang J, et al. Effect of famotidine on the pharmacokinetics of apixaban, an oral direct factor Xa inhibitor. Clin Pharmacol. 2013;5(1):59-66.

30. Raghavan N, Frost CE, Yu Z, et al. Apixaban metabolism and pharmacokinetics after oral administration to humans. Drug Metab Dispos. 2009;37(1):74-81.
31. Zhang D, He K, Raghavan N, et al. Comparative metabolism of 14C-labeled apixaban in mice, rats, rabbits, dogs, and humans. Drug Metab Dispos. 2009;37(8):1738-48.

32. Wang L, He K, Maxwell B, et al. Tissue distribution and elimination of [14C]apixaban in rats. Drug Metab Dispos. 2011;39(2):256-64.

33. Zhang D, Frost $\mathrm{CE}, \mathrm{He} \mathrm{K}$, et al. Investigating the enteroenteric recirculation of apixaban, a factor Xa inhibitor: administration of activated charcoal to bile duct-cannulated rats and dogs receiving an intravenous dose and use of drug transporter knockout rats. Drug Metab Dispos. 2013;41(4):906-15.

34. Chyka PA, Seger D, Krenzelok EP, et al. Position paper: singledose activated charcoal. Clin Toxicol (Phila). 2005;43(2):61-87.

35. Perrier D, Gibaldi M. General derivation of the equation for time to reach a certain fraction of steady state. J Pharm Sci. 1982;71(4):474-5.

36. Zhang D, He K, Herbst J, et al. Characterization of transporters involved in distribution and disposition of apixaban. Drug Metab Dispos. 2013;41(4):827-35.

37. Ferry DG, Gazeley LR, Busby WJ, et al. Enhanced elimination of piroxicam by administration of activated charcoal or cholestyramine. Eur J Clin Pharmacol. 1990;39(6):599-601.

38. Keranen T, Sorri A, Moilanen E, et al. Effects of charcoal on the absorption and elimination of the antiepileptic drugs lamotrigine and oxcarbazepine. Arzneimittelforschung. 2010;60(7):421-6.

39. [No authors listed] Position statement and practice guidelines on the use of multi-dose activated charcoal in the treatment of acute poisoning. American Academy of Clinical Toxicology; European Association of Poisons Centres and Clinical Toxicologists. J Toxicol Clin Toxicol. 1999; 37(6):731-51.

40. Friberg LE, Isbister GK, Hackett LP, et al. The population pharmacokinetics of citalopram after deliberate self-poisoning: a Bayesian approach. J Pharmacokinet Pharmacodyn. 2005; 32(3-4):571-605.

41. Isbister GK, Friberg LE, Hackett LP, et al. Pharmacokinetics of quetiapine in overdose and the effect of activated charcoal. Clin Pharmacol Ther. 2007;81(6):821-7.

42. Osterhoudt KC, Durbin D, Alpern ER, et al. Risk factors for emesis after therapeutic use of activated charcoal in acutely poisoned children. Pediatrics. 2004;113(4):806-10. 